\title{
A Study of Integration ICT into Curriculum in China's Developed Areas-A Case of Foshan City
}

\author{
Weigang Guo ${ }^{1, a^{*}}$ and Zhu Yang ${ }^{2, b}$ \\ ${ }^{1}$ School of Electronic and Information Engineering of Foshan University, Guangdong, China \\ ${ }^{2}$ Information Center of Foshan University, Guangdong, China \\ awgguo@qq.com, byangzhu@fosu.edu.cn
}

Keywords: Information and communication technology; Integration with curriculum; Course coverage; Class coverage; Effectiveness

\begin{abstract}
Integration of information and communication technology (ICT) and subject curriculum is the core of the application of e-education. Taking Foshan city of Guangdong Province as an example, this paper studies the integration of ICT and curriculum in the basic education in the developed areas of China. In this paper, the application of ICT in primary and secondary schools is deeply understood by questionnaire survey, discussion with teachers \& students and on-the-spot investigation. The course coverage, the class coverage and the effectiveness of Integration of ICT and curriculum are investigated and analyzed. The research results show that as the developed areas of China's e-education, the integration of ICT and curriculum in Foshan is much closed, and it is almost full coverage. In the aspect of effectiveness, ICT can effectively improve students' learning interest; improve the efficiency and the quality of classroom teaching, so as to improve the overall quality of students. For the specific effective degree, the school leaders, teachers and students have some differences in their views, and the effectiveness is still relatively subjective. There is no specific indicators which can be clearly confirmed the effectiveness. And, the corresponding research is less. In the future, the research of educational technology in the schools should be strengthened, and the effectiveness of the integration of ICT and curriculum should be paid more attention to.
\end{abstract}

\section{Introduction}

With the development of quality education and the advancement of e-education in China, it is required that information and communication technologies (ICT) education should be universal in primary and secondary schools. The integration of ICT and curriculum has become an inevitable trend of the education. The organic synthesis of ICT and subject teaching can improve the efficiency and effect of teaching and learning to make the traditional teaching mode more perfect. There are a lot related researches in this area in China. Through the investigation and analysis of the current cases, Wei [1] examined the problems faced with ICT and curriculum integration, discusses the relevant countermeasure to promote the effective combination of independent and cooperative learning mode to realize the teaching optimization. Based on field visits and data analysis, Yu [2] summarized the overall status of the integration of ICT and the mathematics curriculum in China Yantai area. Wang [3] did a research on the situation and effect of the application of modern information technology in the biology teaching of junior middle school in Hohhot. Li [4] explored and analyzed some important issues including the essence and function of multimedia in information technology and curriculum integration, the evaluation of integration effect and the phases of integration. Cai [5] focused on the integration of information technology and the primary school's Chinese curriculum, and put forward some pertinent suggestions. He [6] and Zhang [7] proposed that the school should guide teachers to increase the education information infrastructure, encourage the teacher to develop high quality software resources and to provide adequate information technology training for teachers; teaching in the classroom teaching should be based on the teaching objects, features of the subject integration. Deng [8] found that in terms of presentation form, information technology often hinders students from 
deeply understanding the teaching content; in terms of classroom interactions, information technology is likely to hinder the interactions and exchanges between teachers and students. On the basis of a large number of educators' researches, Qiu [9] gave in-depth investigation and analysis of junior high school IT and curriculum integration status in agricultural and pastoral areas of Qinghai by questionnaires and interviews, and put forward strategies aiming at the local status. On the basis of comprehensive understanding and knowledge of information technology and curriculum integration research, $\mathrm{Hu}[10]$ concerned about the level of teaching practice research and objective analysis of the complexity of information technology and curriculum integration. Hou [11] researched the advantages and disadvantages between information technology and curriculum integration with the traditional teaching method were compared.

So we can see that there is little research in the field of the application of information technology in the developed areas of China. This paper mainly takes Guangdong Province Foshan City, one of China's most developed areas, as an example, and investigated and analyzed from the following three aspects: the course coverage of integration ICT into curriculum, the class coverage of integration ICT into curriculum, the effectiveness of integration ICT into curriculum.

\section{Methodology}

The main research method adopted in this paper includes questionnaire survey, discussion with teachers and students and the on-the-spot investigation.

Questionnaire. On the basis of literature research and communicating with the primary and secondary school teachers and educational technology departments, five questionnaires were compiled, including "whole school questionnaire"(69 questionnaires were sent out, and 69 valid questionnaires were recovered), "school administrative leadership questionnaire"(237 questionnaires were sent out, and 225 valid questionnaires were recovered), "information technology teacher questionnaire"(196 questionnaires were sent out, and 186 valid questionnaires were recovered), "ordinary teacher questionnaire"(3475 questionnaires were sent out, and 2835 valid questionnaires were recovered) and "student questionnaire"(6350 questionnaires were sent out, and 292 valid questionnaires were recovered). These five questionnaires are used for different research objects and are helpful to collect data from a different point of view. These questionnaires were carried out in 69 primary and secondary schools in Foshan city online. The reliability and validity of the questionnaires were analyzed. For the data collected by the questionnaires, multiple linear regression analysis, data envelopment analysis and other mathematical models are used to do a lot of detailed statistical analysis.

Discussion with Teachers and Students. The discussion members are including computer teachers, the course leader, backbone teachers, students and teachers with different levels of educational technology ability. The main purpose of discussion is to investigate the influence of ICT to teachers' and students' personal development and the development of the whole school. Discussion is very helpful to find the hidden problems and have a comprehensive understanding of the status quo.

On-the-spot Investigation. The main methods are going to the school to get a real hand materials including listening to the report, visiting the information infrastructure, investigating the classrooms, application software, management system, the teaching process with ICT and the typical cases.

\section{Analysis of Survey Results}

The following is mainly analyzed from the course coverage, the class coverage and the effectiveness of integration of ICT and curriculum.

The Course Coverage of Integration ICT into Curriculum. As long as information and communication technologies are adopted in the course teaching process (not considering the specific hours), it is considered that the curriculum is integrated with information and communication technology. According to the data submitted by the schools, the course coverage of the integration of ICT and curriculum $59.4 \%$ of the surveyed schools reached $100 \%$, namely all courses are integrated. 
And, $81.2 \%$ of the schools reached over $80 \%, 91.3 \%$ of the schools reached more than $50 \%$. It can be seen that the course integration rate is quite high.

In the aspect of teacher integration coverage, $30.5 \%$ of the surveyed schools reached $100 \%$. That is, all the teachers in the curriculum teaching used information and communication technology. $94.9 \%$ of the schools are more than $80 \%$. There is no school's teacher integration coverage less than $50 \%$. Obviously, the teacher integration coverage is very high. As far as teachers are concerned, more than $94 \%$ of the subject teachers use information technology in their own teaching. Only about $6 \%$ of the teachers do not use information technology for teaching.

The Class Coverage of Integration ICT into Curriculum. Class coverage is that as long as the use of information technology in a class (not considering the length of the application time), it is considered the class has integrated with information and communication technology. As shown in Fig.1, there are great differences among teachers on their class coverage. Overall, the time ratio of $57 \%$ of teachers who used information technology while in course teaching is more than $60 \%$. This ratio should be relatively high. It means that, in Foshan City, teachers' enthusiasm in information technology and curriculum integration is very high. For different courses, they are not the same for the use of information technology. Even if for the same subject, the difference of knowledge points will lead to the different use of information technology. While in discussion, most teachers said only when it is necessary to improve teaching efficiency and effectiveness they would use information technology. And too much reliance on information technology will affect the teaching effect. A lot of teachers have been aware of the "reasonable use" of information and communication technology.

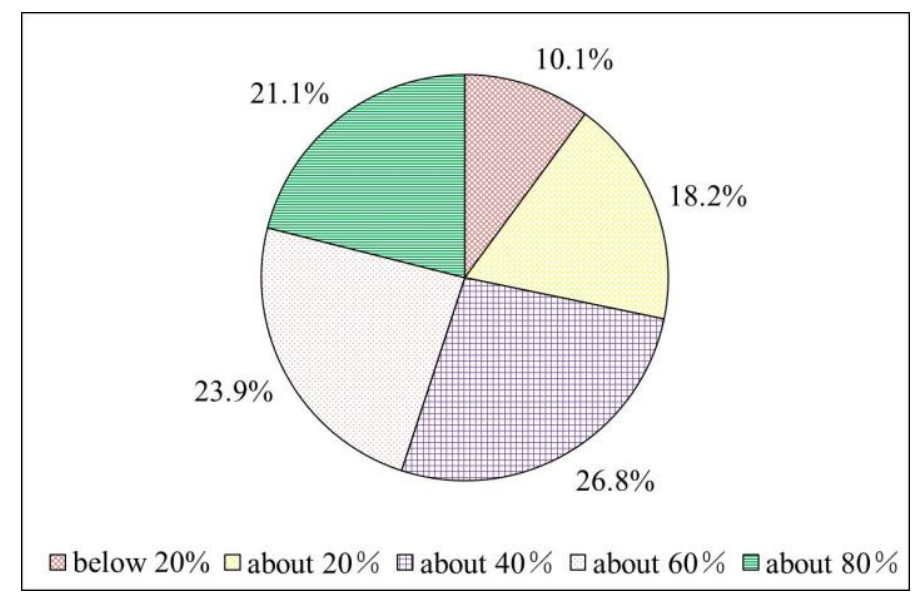

Figure 1. The class coverage of Integration ICT into Curriculum of different teachers

The Effectiveness of Integration ICT into Curriculum. Survey shows that $91.7 \%$ of the school's leaders and $50.8 \%$ of the school's teachers believe that integration of ICT and curriculum greatly improved students' learning interest. About $80 \%$ of the students like the teachers to use the multimedia and network teaching. They think ICT can promote their learning interest and enthusiasm. But, It should be mentioned that there are also about $20 \%$ of the students having little interest on the integration of ICT and Curriculum.

In the improvement of student achievement, as shown in Fig.2, there are $71.7 \%$ of the school's leaders think that the integration of ICT and curriculum is more effective in improving the students' scores, while only $23.7 \%$ of the school teachers believe that there is a great improvement. From the perspective of students, you can see the students have a clear tendency. Nearly $97 \%$ of the students think that information technology can improve their scores.

In the professional growth of teachers, more than $90 \%$ of the school's leaders believe that in the integration of information technology and curriculum, teachers need pay more extra time and energy. And along with the process, the promotion of the professional growth of teachers is also obvious. Teachers think it's worth it. Fig. 3 show that $98.3 \%$ of the school teachers think that their spent on 
working in information technology and curriculum integration time is worth, only $1.7 \%$ of the schools consider that is not worth.

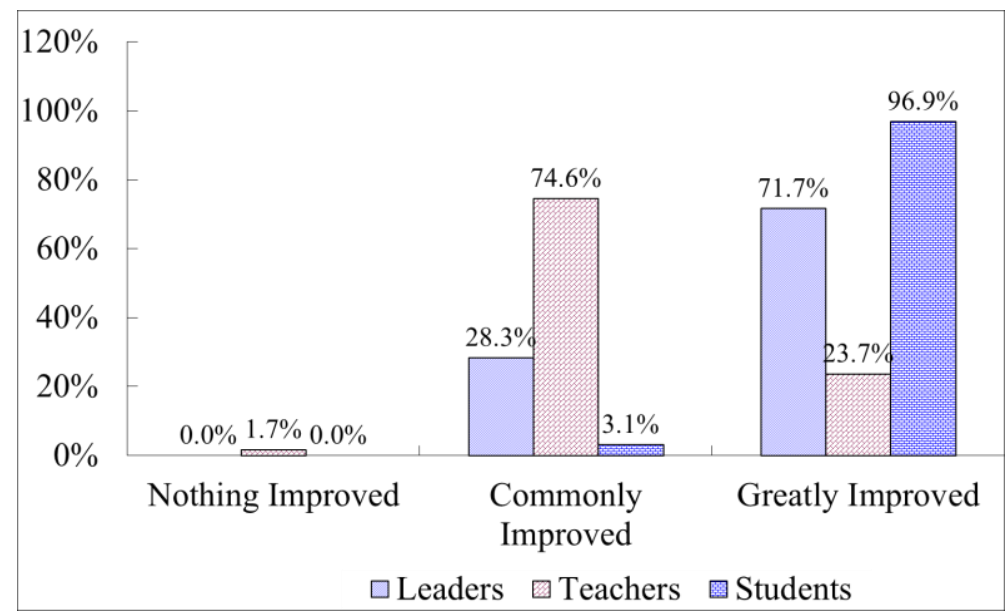

Figure 2. The view of leaders, teachers and students to the effectiveness to students' scores

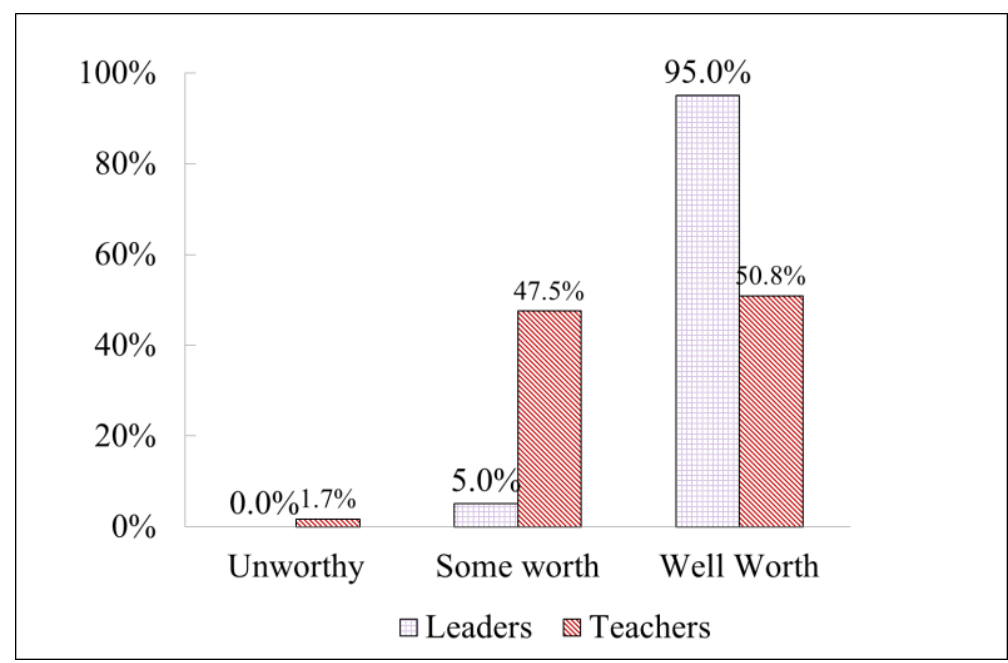

Figure 3. ICT to promote teachers' professional growth from the view of leaders and teachers

\section{Features, Problems and Suggestions}

Features and Advantages. There are high course coverage and class coverage of integration of ICT and curriculum in all types of schools at all levels. Almost all the subjects of all types of schools at all levels are applied information technology. Teachers can use information technology in teaching. ICT and curriculum integration has become a conventional teaching methods and habits. There are a variety of information technology and curriculum integration models and a large number of outstanding cases. Most of the schools carried out many teaching experiments, such as research learning, autonomous learning, cooperative learning, etc.

Existing Problems. In the integration of information technology with curriculum, there is still a lack of convincing proof for the effect of integration. And there is less control experiment. Schools and teachers which can systematically do the integration teaching experiments are not much. It is needed to pay more attention to the professional development of the large number of ordinary teachers, to promote their rapid growth in the information environment.

Related Suggestions. First, the emphasis should be focused on improving the effectiveness of ICT and curriculum integration, not merely the coverage rate. Second, as only about half of the school teachers think that information technology has obviously helpful to their own growth, the leaders 
should continue to provide high quality network teaching resources and training to accelerate the growth of the ordinary teachers. Third, Foshan Bureau of Education should encourage teachers to carry out educational technology research and provide more funding.

\section{Conclusions}

As one of China's most developed areas, integration of ICT and curriculum has become the norm in Foshan today. But the obtained achievement of information technology in promoting the comprehensive development of students, improving the level of school and class management, and the teachers' professional growth is insufficient. More efforts should be paid so as to get more output of the application of information technology. Next, big data technology will be used to collect, manage and analyze the effect of ICT and curriculum integration, in order to make the results of the study more practical and valuable.

\section{Acknowledgements}

This work is completed under the support of the Foshan Bureau of Education "Intelligent Education Evaluation System Optimization and Upgrading Service"(No. 0658-1501SZTCE279).

\section{References}

[1] Y.N. Wei, Study on the integration of Information Technology and Curriculum (MS., Xibei Normal University, China 2014), 8-12. (In Chinese)

[2] H.J. Yu, Research and Analysis of Information Technology and Mathematics Curriculum Integration of the Yantai (MS., Ludong University, China 2012), 5-13. (In Chinese)

[3] Y.Q. Wang, Situation Investigation and Analysis on integration of information technology and junior high school biology curriculum -With Hohhot schools as examples (MS., Inner Mongolia Normal University, China 2015), 6-15. (In Chinese)

[4] Z.Y. Li, The Basic Problems on Integration of Information Technology and Curriculum. Educational Research, Vol. 36 (2015) No.11, 91-97.

[5] C. Cai, Thinking about the Integration of Information Technology and Chinese Curriculum in Primary Schools. The Guide of Science \& Education, Vol. 8 (2016) No.04, 141-142.

[6] R.J. He, On Educational Technology Information Technology and Curriculum Integration. Modern Educational Technology, Vol. 20 (2010) No.10, 41-43.

[7] Q.H. Zhang, The problems and countermeasures in the integration of information technology and curriculum. Journal of Jiamusi Education Institute, Vol. 10 (2012) No.10, 5-11.

[8] Z.X. Deng, Significance and Existing Problems of the Integration between Information Technology and Chinese Curriculum in Primary and Middle Schools, proceedings of the Conference on Management Innovation. Intelligent Technology and Economic Development, July,2012, 151-155.

[9] H.X. Qiu, The Study of Junior High School Information Technology and Curriculum Integration in Qinghai Agricultural and Pastoral Areas(MS., Xi'nan University, China 2012), 6-13. (In Chinese)

[10]C.X. Hu, Research and Reflection on information technology and curriculum integration (MS., Hebei Normal University, China 2013), 8-15. (In Chinese)

[11] C.G. Hou, W. Xin, Exploring Integration of Information Technology and High School Math Curriculum. Yinshan Academic Journal, Vol. 29 (2015) No.01, 88-91. 